\title{
Is being small for gestational age a risk factor for strabismus and refractive errors at 3 years of age?
}

\author{
İkbal Seza Petriçli ${ }^{1 \oplus}$, Caner Kara $^{1 \oplus}$, Ayşegül Arman ${ }^{2 \oplus}$ \\ ${ }^{1}$ Department of Ophthalmology, Etlik Zübeyde Hanim Women's Health Training and Research Hospital, Ankara; ${ }^{2}$ Department of \\ Ophthalmology, Bilkent City Hospital, Ankara, Turkey.
}

\begin{abstract}
Background. Visual problems, cerebral visual impairment, refractive errors and strabismus are commonly found in preterm infants in long-term follow-ups. The aim of this study was to determine the factors that lead to the development of amblyogenic risk factors, such as high refractive errors, anisometropia and strabismus, in the long-term evaluation of preterm infants.

Methods. We retrospectively evaluated children who were screened for retinopathy of prematurity (ROP) and who had a 3rd year ophthalmologic examination. The impacts of sex, gestational age (GA), birth weight (BW), BW for GA, being small for gestational age (SGA), being appropriate for gestational age (AGA), multiple pregnancies and the results of ROP screening on refractive errors and the development of strabismus were evaluated by logistic regression analysis. The SGA and AGA groups were compared in terms of refractive errors and presence of strabismus.

Results. Six hundred and eight children, including 317 (52.1\%) males and 291 (47.9\%) females, were included in the study. The mean GA was $31 \pm 3$ weeks (24-36), and the mean BW was $1505 \pm 435 \mathrm{~g}$ (600-2460). The number of SGA-born children was 101 (16.6\%). Manifest deviation was detected in 42 (5.6\%) children, and optical correction was required in 101 (16.6\%) children. Being an SGA infant and multiple pregnancies were risk factors for refractive errors requiring optical correction, and hyperopia ( $\geq 3.00 \mathrm{D})$ was found to be a risk factor for the development of strabismus in the multivariate regression analysis. Additionally, the SGA group was at high risk for strabismus, hyperopia, high astigmatism and the need for optical correction.
\end{abstract}

Conclusions. We concluded that SGA seems to be associated with an increased risk of strabismus and a high refractive error. It should be taken into consideration during follow-up examinations of SGA infants.

Key words: premature, retinopathy of prematurity, refractive error, small for gestational age, strabismus.

Visual problems, cerebral visual impairment, refractive errors, strabismus, color vision and visual field defects are more commonly encountered in preterm infants than in term infants in long-term ophthalmologic evaluations because of the unfavorable effects of prematurity on visual and neurologic development. ${ }^{1}$ The severity of refractive errors and the incidence of strabismus increase with lower gestational ages and birth weights and with the presence

\section{İkbal Seza Petriçli}

seza0906@yahoo.com

Received 20th December 2019, revised 19th February 2020, accepted 20th March 2020. and progression of retinopathy of prematurity (ROP) ${ }^{2-5}$ Gulati et al. ${ }^{6}$ demonstrated that having low birth weight, independent of gestational age, had a significant role in the development of strabismus. Thus, premature infants and those with low birth weight should be followed regularly after the completion of ROP screening to detect refractive errors and strabismus as well as to prevent the development of amblyopia. ${ }^{7}$

Refractive errors in children are determined by the emmetropization process, which is closely related to the changes in the axial length of the eye and the corneal curvature. Studies on the effects of birth parameters on the emmetropization process have shown that 
children (aged 7-9 years) who are born more mature with higher birth weights and larger head circumferences had longer axial lengths, which did not affect the refractive error because of the flattening of the cornea and a decrease in the corneal refractive power. ${ }^{8}$ Another study showed that children born with longer axial lengths had relatively slower increases in the axial length of the eye during the first 3 years of life, and this did not affect the development of refractive errors. ${ }^{9}$ Mutti et al. ${ }^{10}$ indicated that refractive errors at birth are important in the emmetropization process.

Infants small for gestational age (SGA) in terms of their birth weight are associated with high morbidity and mortality during the prenatal and neonatal periods. ${ }^{11,12}$ Both SGA and preterm infants have high risks of developing severe ROP. ${ }^{13,14}$ In addition, SGA infants have high risks for neurodevelopmental deficits, cerebral palsy, low visual acuity, blindness, deafness, mental retardation and low academic performance in long-term evaluations. ${ }^{15-19}$ Being both SGA and preterm increases these risks even more. Gur et al. ${ }^{20}$ showed that the delivery of a term SGA infant was an independent risk factor for longterm ophthalmic morbidity, including ocular inflammation and infections, visual problems and ophthalmic hospitalization. Children born SGA have been shown to have a high risk of developing hyperopia, which may be related to the smaller globe size and the presence of factors causing fetal growth retardation..$^{21,22}$

Although there are many studies on the effect of birth weight and prematurity on long-term ophthalmologic development, studies on the effect of being an SGA infant on long-term ophthalmologic development are limited. Those studies either included a small sample size or included only term or term-preterm infants. ${ }^{18}$, 20-25

In our country, the national vision screening program recommends scanning for amblyopia risk in individuals 3 to 5 years old. ${ }^{26}$ American Academy of Ophthalmology, American Academy of Pediatrics and U.S. Preventive
Services Task Force recommend screening children for amblyopia and its risk factors at least once when they are between ages 3 and 5 years to detect cases of amblyopia or its risk factors (B category; strong recommendation). ${ }^{27,28}$

In this retrospective study, we evaluated the ophthalmologic examination results of 3-yearold children who were screened for ROP in the neonatal period. We aimed to identify amblyogenic risk factors such as high refractive errors, anisometropia and strabismus and compare SGA and appropriate for gestational age (AGA) premature infants in terms of these risk factors.

\section{Material and Methods}

This study was performed in accordance with the principles outlined in the Declaration of Helsinki after it was approved by the Ethics Committee of Etlik Zübeyde Hanım Women's Health Education and Resarch Hospital and registered with the report number 90057706799 on March 22, 2019. Informed consent was obtained from all individual participants included in the study. A retrospective review was conducted on the medical files of patients undergoing the ROP screening program. Patients who had ophthalmologic examinations at 3 years of age were included in the study. Children who developed cerebral palsy related to periventricular leukomalacia and were treated for ROP were excluded from the study because of the possible effects of these factors on the refractive status of the eye. The patient files were evaluated retrospectively; the sex, gestational age, birth weight, ROP screening results, presence and type of multiple pregnancies, refractive status and presence and type of strabismus were recorded. Infants with birth weights below the 10th percentile according to the Fenton Growth Chart were considered SGA, and those above the 10th percentile were considered AGA. ${ }^{29}$

In our ROP clinic, we screened all infants with birth weights $\leq 1500 \mathrm{~g}$ and gestational ages 
of $\leq 32$ weeks and selected infants who were considered to be at risk by the Neonatology Clinic. ROP examinations were performed under topical anesthesia with an indirect binocular ophthalmoscope (Omega 2C, Heine, Germany) and a 20 diopter (D) lens (Volk Double Aspheric, USA). The findings of the ROP screening were recorded according to the guidelines of the International Classification of ROP study. ${ }^{30}$

At the examination performed in children at 3 years of age, fixations, smooth pursuit eye movements, the results of the Hirshberg test for manifest deviations, results of the cover test and prism cover test for latent and manifest deviations, results of the anterior segment evaluations, cycloplegic refractions and results of the retinal examinations were recorded. Cycloplegia was induced by a drop of proparacaine hydrochloride $0.5 \%$ (Alcaine, Alcon, USA) followed by two drops of cyclopentolate hydrochloride 1\% (Sikloplejin, Abdi İbrahim, Turkey). Retinal examinations were performed by indirect binocular ophthalmoscopy and a $20 \mathrm{D}$ lens.

The spherical equivalent (SE) was used to calculate the myopic and hypermetropic refractive errors and was calculated by adding the spherical power and half of the astigmatic power. The American Academy of Ophthalmology pediatric eye evaluation preferred practice pattern guidelines were used for refractive correction. ${ }^{28}$ The significantly high refractive error values, cut off values for anisometropia and optical correction values are shown in Table I. The astigmatic refractive errors were recorded as negative cylindrical values. The axes of astigmatism $(\geq 1.00 \mathrm{D})$ were divided into three classes: with the rule (WTR) astigmatism $0-15^{\circ}$ and $165-180^{\circ}$, against the rule (ATR) astigmatism $75-105^{\circ}$ and oblique astigmatism $16-74^{\circ}$ and $106-164^{\circ}$.

\section{Statistical analysis}

Statistical analysis was performed using SPSS v.21.0 for Windows (IBM Corp. Released 2012,
IBM SPSS Statistics for Windows, Version 21.0 Armonk, NY: IBM Corp.). Continuous variables are presented as the mean $\pm \mathrm{SD}$; categorical variables are defined as numbers and percentages. Chi-square test was used for categorical variables. Because there was a strong correlation between the refractive errors of the right and left eyes, only data from the right eyes were analyzed (Pearson's r=0.96). KolmogorovSmirnov and Shapiro-Wilk tests were used to evaluate the distributions of the data. The differences between the means were evaluated by t-test for normally distributed data and by Mann-Whitney $U$ test for data not normally distributed. Additionally, multivariate logistic regression analysis was used to identify factors significantly associated with strabismus and refractive errors requiring optical correction. Multivariate logistic regression analysis was used for the variables identified as statistically significant $(p<0.10)$ in the univariate analysis. Differences were considered statistically significant when $\mathrm{p}<0.05$.

\section{Results}

In the retrospective evaluation of the patient files, 608 children who met the study criteria were identified. Overall, 317 of them were male $(52.1 \%)$, and 291 of them were female (47.9\%). The mean gestational age was $31 \pm 3$ weeks (2436 weeks), and the mean birth weight was 1505 $\pm 435 \mathrm{~g}(600-2460 \mathrm{~g})$ overall. In terms of the birth weight, 101 children (16.6\%) were SGA, and 507 children $(83.3 \%)$ were AGA infants. The rate of multiple pregnancies was $49.8 \%(\mathrm{n}=300)$; $90 \%(n=270)$ of them were twin pregnancies, $8.3 \%(n=25)$ were triplet pregnancies, and $1.8 \%$ $(n=5)$ were quintuplet pregnancies. ROP was detected in 145 (23.8\%) children, and all of them spontaneously regressed during the follow-up period.

The mean SE of the whole group was $1.66 \pm 1.49$ D. The mean SE for the SGA group was $2.12 \pm$ $1.80 \mathrm{D}$, and that for AGA group was $1.53 \pm 1.41$ $\mathrm{D}(\mathrm{p}=0.04$, Mann-Whitney U test). Significant refractive error according to the SE was found 
in $127(20.8 \%)$ children, including myopia $(\mathrm{n}=$ $42)$ and hyperopia $(n=85)$. Astigmatism $\geq 1.00$ $\mathrm{D}$ was detected in $224(36.8 \%)$ children, 166 $(27.3 \%)$ children had significant astigmatism (1.00-2.00 D), and $58(9.5 \%)$ children had high astigmatism $(\geq 2.00 \mathrm{D})$. A total of $84.9 \%(\mathrm{n}=174)$ had WTR astigmatism, 6.8\% $(\mathrm{n}=14)$ had ATR astigmatism, and $8.3 \%(\mathrm{n}=17)$ had oblique astigmatism.

Optical correction was needed in 101 (16.6\%) children. Among them, 30 (29.7\%) children had both strabismus and refractive error, 23 $(22.8 \%)$ children had high astigmatism, 17 (16.8) children had anisometropia, 16 (15.8\%) children had high hyperopia and 15 (14.9\%) children had both high hyperopia and high astigmatism. Anisometropia $(\geq 1.00$ D) was detected in 51 $(8.3 \%)$ children. Significant anisometropia (1.00-2.00 D) was seen in 31 (5\%) children, and high anisometropia ( $\geq 2.00 \mathrm{D})$ was seen in $20(3.3 \%)$ children. Strabismus was diagnosed in $34(5.6 \%)$ children, $26(76.5 \%)$ of them had esotropia, 7 (20.6\%) of them had exotropia and $1(2.9 \%)$ child had hyperopia.

Risk factors, which may affect refractive errors requiring optical correction and the development of strabismus, were evaluated by univariate and multivariate logistic regression analyses and are given in Table II and Table III, respectively. Multivariate logistic regression analysis showed a strong association between SGA and refractive errors requiring optical correction (OR: 0.37, 95\% Cl 0.22-0.62, p $<0.01$ ) and between multiple pregnancies and refractive errors requiring optical correction (OR: 0.62, 95\% Cl 0.39-0.98, p = 0.04). A statistically significant correlation was detected between the presence of hyperopia ( $\geq 3.00 \mathrm{D}$ ) and the presence of strabismus in the univariate logistic regression analysis.

A comparison of the demographic and clinical characteristics of patients with SGA $(n=101)$ and AGA $(n=507)$ is given in Table IV. Although the mean gestational age of the SGA group was higher than that of the AGA group, the number of children with strabismus, significant hyperopia, high astigmatism or refractive errors requiring optical correction were significantly higher in the SGA group (Table IV).

\section{Discussion}

The ophthalmologic examinations performed at 3 years of age in children who were born premature and screened and followed up for ROP revealed that $5.4 \%$ had strabismus and $16.6 \%$ had refractive errors requiring optical correction in our study. Logistic regression analysis revealed that multiple pregnancies and being an SGA infant were risk factors for refractive errors requiring optical correction and that the presence of significant hyperopia $(\geq 3.00 \mathrm{D})$ was a risk factor for the development of strabismus. The mean SE was statistically more hypermetropic in the SGA group compared to the AGA group, and the number of children with strabismus, significant hyperopia, high astigmatism and refractive errors requiring optical correction were statistically higher in the SGA group compared to the AGA group.

Studies on preterm infants with ROP that either spontaneously regressed or required treatment showed an increase in the incidence of myopia, anisometropia, astigmatism and strabismus in these infants. ${ }^{27,31}$ In our study, the incidence of myopia was $6.9 \%(n=42)$, but optical correction

Table I. Cut-off values for refractive errors used in the study.

\begin{tabular}{lcccc}
\hline Variables & Significant refractive error & High refractive error & Anisometropia & Optical correction \\
\hline Hyperopia (+, D) & $\geq 3.00^{*}$ & $\geq 5.00^{*}$ & $\geq 1.50^{*}$ & $\geq 4.50$ (no deviation) \\
& & & & $\geq 1.50$ (with deviation) \\
Myopia (-, D) & $\leq 0.25^{*}$ & $\leq 3.00^{*}$ & $\leq 3.00^{*}$ & $\leq 3.00$ \\
Astigmatism (-, D) & $\geq 1.00$ & $\geq 2.00$ & $\geq 2.00$ & $\geq 2.00$ \\
\hline
\end{tabular}

D: diopter; *: spherical equivalent 
Table II. Logistic regression analysis for factors associated with refractive errors requiring optical correction.

\begin{tabular}{lcccccc}
\hline \multirow{2}{*}{ Variables } & \multicolumn{3}{c}{ Univariate analysis } & \multicolumn{3}{c}{ Multivariate analysis } \\
\cline { 2 - 7 } & $\mathrm{p}$ & $\mathrm{OR}$ & $(95 \mathrm{CI})$ & $\mathrm{p}$ & $\mathrm{OR}$ & $(95 \mathrm{CI})$ \\
\hline Gestational age & 0.01 & 0.01 & $(1.02-1.11)$ & 0.24 & 1.05 & $(0.96-1.14)$ \\
Birth weight & 0.86 & 1.00 & $(0.99-1.00)$ & - & - & - \\
Small for gestational age & $<0.01$ & 0.36 & $(0.22-0.59)$ & $<0.01$ & 0.37 & $(0.22-0.62)$ \\
Multiple pregnancy & 0.02 & 0.61 & $(0.40-0.95)$ & 0.04 & 0.62 & $(0.39-0.98)$ \\
Sex & 0.94 & 1.02 & $(0.66-1.56)$ & - & - & - \\
Retinopathy of prematurity & 0.98 & 1.01 & $(0.61-1.66)$ & - & - & - \\
Gestational age $\leq 27$ weeks & 0.22 & 1.40 & $(0.81-2.39)$ & - & - & - \\
Birth weight $\leq 1000$ g & 0.28 & 0.72 & $(0.40-1.30)$ & - & - & - \\
\hline
\end{tabular}

OR: Odds ratio, CI: confidence interval.

Table III. Logistic regression analysis for factors associated with strabismus.

\begin{tabular}{|c|c|c|c|c|c|c|}
\hline \multirow{2}{*}{ Variables } & \multicolumn{3}{|c|}{ Univariate analysis } & \multicolumn{3}{|c|}{ Multivariate analysis } \\
\hline & $\mathrm{p}$ & OR & $(95 \mathrm{CI})$ & $\mathrm{p}$ & OR & $(95 \mathrm{CI})$ \\
\hline Gestational age & 0.02 & 1.17 & $(1.02-1.34)$ & 0.14 & 1.20 & $(0.96-1.30)$ \\
\hline Birth weight & 0.76 & 1.00 & $(0.99-1.00)$ & - & - & - \\
\hline Small for gestational age & $<0.01$ & 2.97 & $(1.42-6.22)$ & 0.07 & 0.37 & $(0.22-0.62)$ \\
\hline Multiple pregnancy & 0.78 & 1.10 & $(0.55-2.20)$ & - & - & - \\
\hline Sex & 0.65 & 1.17 & $(0.58-2.35)$ & - & - & - \\
\hline Retinopathy of prematurity & 0.71 & 0.86 & $(0.39-1.89)$ & - & - & - \\
\hline Gestational age $\leq 27$ weeks & 0.67 & 1.20 & $(0.51-2.81)$ & - & - & - \\
\hline Birth weight $\leq 1000 \mathrm{~g}$ & 0.21 & 1.60 & $(1.02-1.34)$ & - & - & - \\
\hline Hyperopia ( $\geq 3.00 \mathrm{D}$ ) & $<0.001$ & 0.12 & $(0.05-0.24)$ & $<0.001$ & 0.14 & $(0.06-0.30)$ \\
\hline Myopia( $\leq 0.25 \mathrm{D})$ & 0.99 & 0.00 & $(0.00-;)$ & - & - & - \\
\hline Astigmatism ( $\geq 2.00 \mathrm{D})$ & 0.10 & 2.15 & $(0.85-5.43)$ & 0.82 & 0.88 & $(0.31-2.48)$ \\
\hline Anisometropia ( $\geq 2.00 \mathrm{D})$ & 0.02 & 0.49 & $(0.18-1.34)$ & 0.17 & 0.38 & $(0.09-1.54)$ \\
\hline
\end{tabular}

OR: Odds ratio, CI: confidence interval

was not required (myopia $\leq 3.00 \mathrm{D}$ ). Children who needed optical correction had one of the following diagnoses: highhyperopia, strabismus with refractive errors, high astigmatism or anisometropia. Holmstrom et al. ${ }^{7}$ detected astigmatism at a corrected age of 30 months in $26 \%$ of the premature infants included in their study, and they showed that ATR was the most common type. The incidence of astigmatism was $33.7 \%$ in our study, and WTR astigmatism was the most common type $(84.9 \%)$. The incidence of high astigmatism was $7.7 \%$ overall, and the incidence of high astigmatism in the SGA group was statistically higher than that in the AGA group. Additionally, the mean SE was statistically more hypermetropic in the SGA group. Rutstein et al. ${ }^{23}$ showed that the average spherical refractive error for intrauterine growth-retarded infants was approximately $0.50 \mathrm{D}$ more hypermetropic compared to that in normal birth weight infants. There are studies supporting this finding that being an SGA infant is a risk factor for the development of hyperopia during adolescence. ${ }^{21,22}$ In our study, the number of children with hyperopic refractive errors was significantly higher in the SGA group than in the AGA group. The progression of refractive errors in children is determined by the emmetropization process, which is closely related to changes in the axial length of the eye and refractive powers of the cornea and lens. Studies on the emmetropization process showed 
Table IV. Comparison of demographic and clinical characteristics of patients with SGA and AGA.

\begin{tabular}{|c|c|c|c|c|}
\hline Variables & & SGA $(n=101)$ & AGA $(n=507)$ & $p$ value \\
\hline Gestational age (week) & Mean \pm SD & $32 \pm 3$ & $30 \pm 3$ & $<0.01$ \\
\hline & (Range) & $(25-36)$ & $(24-36)$ & \\
\hline Birth weight (g) & Mean \pm SD & $1260 \pm 396$ & $1554 \pm 426$ & $<0.01$ \\
\hline & (Range) & $(600-2190)$ & $(690-2460)$ & \\
\hline Sex & Male; n (\%) & $37(36.6)$ & $280(55.2)$ & $<0.01$ \\
\hline & Female; n (\%) & $64(63.4)$ & $227(44.8)$ & \\
\hline Multiple pregnancy & n (\%) & 44 (43.6) & $256(50.5)$ & \\
\hline Strabismus & $\mathrm{n}(\%)$ & $12(11.9)$ & $22(4.3)$ & 0.20 \\
\hline Retinopathy of prematurity & n (\%) & $27(26.7)$ & $118(23.3)$ & 0.03 \\
\hline Spherical equivalent (D) & Mean \pm SD & $2.12 \pm 1.80$ & $1.53 \pm 1.41$ & 0.45 \\
\hline & (Range) & $(-1.50$ to 10.00$)$ & $(-2.75$ to 8.75$)$ & 0.04 \\
\hline Refractive error & & & & \\
\hline Hyperopia $(\geq 3.00 \mathrm{D})^{*}$ & n (\%) & $23(22.8)$ & $62(12.2)$ & 0.005 \\
\hline Myopia $(\leq 0.25)^{*}$ & n (\%) & $5(5.0)$ & $37(7.3)$ & 0.39 \\
\hline Astigmatism ( $\geq 1.00 \mathrm{D})$ & n (\%) & $51(50.5)$ & $173(34.1)$ & $<0.01$ \\
\hline Astigmatism (1.00-2.00 D) & n (\%) & $33(32.7)$ & $133(26.2)$ & 0.18 \\
\hline Astigmatism ( $\geq 2.00 \mathrm{D})$ & n (\%) & $18(17.8)$ & $40(7.9)$ & $<0.01$ \\
\hline Anisometropia ( $\geq 1.00 \mathrm{D})$ & n $(\%)$ & $7(6.9)$ & $44(8.7)$ & 0.36 \\
\hline Anisometropia (1.00-2.00 D) & $\mathrm{n}(\%)$ & $3(2.9)$ & $28(5.5)$ & 0.13 \\
\hline Anisometropia ( $\geq 2.00 \mathrm{D})$ & $\mathrm{n}(\%)$ & $4(4.0)$ & $16(3.2)$ & 0.67 \\
\hline Optical correction & $\mathrm{n}(\%)$ & $31(30.7)$ & $70(13.8)$ & $<0.001$ \\
\hline
\end{tabular}

AGA: appropriate for gestational age, D: Diopter, SD: standard deviation, SGA: small for gestational age, *: spherical equivalent

that children finally became emmetropic with subsidiary changes in these parameters in long-term evaluations. ${ }^{8,9}$ Mutti et al. ${ }^{10}$ stated that the refractive error at birth is important in the emmetropization process. Özdemir et al. ${ }^{32}$ revealed that the axial length shortens as gestational age and birth weight decreased in prematurely born children (5-7 years) who did not develop ROP. Since the refractive state is corrected by the emmetropization process, no significant refractive error develops in these children. We detected statistically significantly more hyperopia in children born SGA than those born AGA. This result may have results from shorter axial lengths in SGA infants. Additionally, factors causing intrauterine growth retardation may adversely affect the emmetropization process in these children. Lim et al. ${ }^{9}$ showed that infants with longer axial lengths had smaller increases in the axial length in the first 3 years of life and that this condition did not cause refractive errors. Studies have revealed that SGA infants have a higher risk of low visual acuity, blindness, deafness, neurodevelopmental deficits, cerebral palsy and mental retardation compared to AGA infants. ${ }^{15-18,33}$ Although the mean gestational age in the SGA group was higher than that in the AGA group in our study, the incidence of strabismus and refractiveerrors requiring optical correction were statistically significantly higher in the SGA infants. Studies comparing preterm SGA, term SGA and term AGA infants revealed that the preterm SGA group had worse visual functions and more cases of strabismus than the term AGA group, but there was no statistically significant difference between the term AGA and term SGA groups. ${ }^{22,24,25}$ Similarly, Rutstein et $a 1 .{ }^{23}$ did not find any significant difference between the term intrauterine growth-retarded 
group and term normal birth weight group, but they did not include a preterm SGA group for comparison.

Studies have shown that functional vision, visual motor integration and academic performance are adversely affected in children born SGA, even in those without major neurologic problems. ${ }^{19,33,34}$ It has been shown that these functions are much more adversely affected in SGA-born children than in AGA-born children. ${ }^{33,34}$ Ley et al. ${ }^{35}$ proposed that thinning detected in the neuroretinal rim in young adults born SGA because of intrauterine growth retardation could be due to the loss of axons in the optic nerve caused by fetal circulatory insufficiency. Additionally, Thordstein et al. $^{36}$ showed an increase in the latency of visual evoked potentials (VEPs) in intrauterine growth-retarded children, and they proposed that this increased latency may be an indicator of adversely affected intrauterine brain development. Pinello et al. ${ }^{18}$ found that SGA infants had lower visual acuity, as measured with Teller Acuity Cards, and lower mental performance, as measured with the Bayley Scale of Infant Development, compared to AGA infants at 1 year of age. This study was performed in a small patient group $(\mathrm{n}=17)$, and refractive errors were not included. Additionally, it was not stated whether refractive errors were corrected or not in the evaluation of visual acuity. Although visual acuity was not evaluated in our study, the incidence of refractive errors and optical correction were higher in the SGA group than in the AGA group. Overall, being SGA was a risk factor for the development of refractive errors requiring optical correction.

The incidence of strabismus in childhood varies (2-26\%) across studies according to the GA and $\mathrm{BW}$ of the child and the presence of ROP and cerebral palsy. Studies have revealed a strong correlation across the birth weight, gestational age and strabismus incidence. ${ }^{6,31,37-39}$ In the Millennium Cohort Study ${ }^{39}$, which was carried out in the United Kingdom, 14980 children aged 3 years were screened, and the incidence of strabismus was found to be $2.1 \%$. The incidence was $4.6 \%$ in the gestational age-matched and birth weight-matched group in our study $(\mathrm{GA}<37$ weeks, $\mathrm{BW}<2500 \mathrm{~g})$. Gulati et al. ${ }^{6}$, in a study in a large population of prematurely born children ( $n=38055)$, revealed the incidence of strabismus to be $3 \%$ and stated that low birth weight was an independent risk factor for the development of strabismus. Robaei et al. ${ }^{40}$ stated that low birth weight infants (1500$2500 \mathrm{~g}$ ) were at increased risk of developing amblyopia, anisometropia and strabismus compared to normal birth weight infants $(\geq 2500$ g) during childhood. Gur et al. ${ }^{20}$ showed that being an SGA infant is an independent risk factor for long-term ocular morbidity (up to 18 years after delivery). They found that the SGA group were at a higher risk for strabismus and amblyopia than the AGA group. Fieß et al. ${ }^{41}$ detected strabismus in $17.5 \%$ of the individuals aged $4-10$ years in the preterm group (GA $\leq 37$ weeks) and found that GA, hyperopia ( $\geq 3.00$ D), and astigmatism were risk factors for the development of strabismus. We detected the incidence of strabismus to be $11.9 \%$ in the SGA group and $4.3 \%$ in the AGA group ( $p=0.03$ ). Hyperopia ( $\geq 3.00 \mathrm{D}$ ) was a significant risk factor for the development of strabismus according to the logistic regression analysis. Consistent with our findings, different studies have revealed that hyperopia is a risk factor for strabismus. ${ }^{42,43}$ In our study, SGA infants had statistically significantly higher hyperopia, which may be an important risk factor for the development of strabismus in this group.

One of the limitations of our study is that visual acuity was not evaluated because of the retrospective nature of the study. Additionally, ocular biometric measurements could not be performed, and factors causing intrauterine growth retardation could not be evaluated. On the other hand, the large sample size and comparison of SGA and AGA preterm groups are the major strengths of this study.

In conclusion, preterm-born children have a high risk for refractive errors, and being SGA increases this risk even more. It is advised 
that preterm infants are closely followed up after the completion of ROP screening for high refractive errors and strabismus to prevent the development of amblyopia. ${ }^{44}$ We suggest that pediatricians and ophthalmologists are informed that both children born preterm and those born SGA are at high risk for developing strabismus, high hyperopia and high astigmatism and should be closely and regularly examined for amblyogenic risk factors.

\section{REFERENCES}

1. O'Connor AR, Wilson CM, Fielder AR. Ophthalmological problems associated with preterm birth. Eye (Lond) 2007; 21: 1254-1260.

2. Al Oum M, Donati S, Cerri L, Agosti M, Azzolini C. Ocular alignment and refraction in preterm children at 1 and 6 years old. Clin Ophthalmol 2014; 8: 12631268.

3. Choi MY, Park IK, Yu YS. Long term refractive outcome in eyes of preterm infants with and without retinopathy of prematurity: comparison of keratometric value, axial length, anterior chamber depth, and lens thickness. Br J Ophthalmol 2000; 84: 138-143.

4. O'Connor AR, Stephenson TJ, Johnson A, Tobin MJ, Ratib S, Fielder AR. Strabismus in children of birth weight less than $1701 \mathrm{~g}$. Arch Ophthalmol 2002; 120: 767-773.

5. Cotter SA, Varma R, Tarczy-Hornoch K, et al; Joint Writing Committee for the Mul-ti-Ethnic Pediatric Eye Disease Study and the Baltimore Pediatric Eye Disease Study Groups Risk factors associated with childhood strabismus: the multi-ethnic pediatric eye disease and Baltimore pediatric eye disease studies. Ophthalmology 2011; 118: 2251-2261.

6. Gulati S, Andrews CA, Apkarian AO, Musch DC, Lee PP, Stein JD. Effect of gestational age and birth weight on the risk of strabismus among premature infants. JAMA Pediatr 2014; 168: 850-856.

7. Holmstrom M, el Azazi M, Kugelberg U. Ophthalmological long-term follow up of preterm infants: a population based, prospective study of the refraction and its development. Br J Ophthalmol 1998; 82: 1265-1271.
8. Saw SM, Tong L, Chia KS, et al. The relation between birth size and the results of refractive error and biometry measurements in children. Br J Ophthalmol 2004; 88: 538-542.

9. Lim LS, Chua S, Tan PT, et al. Eye size and shape in newborn children and their relation to axial length and refraction at 3 years. Ophthal Physl Opt 2015; 35: 414-423.

10. Mutti DO, Mitchell GL, Jones LA, et al. Axial growth and changes in lenticular and corneal power during emmetropization in infants. Invest Ophthalmol Vis Sci 2005; 46: 3074-3080.

11. Boghossian NS, Geraci M, Edwards EM, Horbar JD. Morbidity and mortality in small for gestational age infants at 22 to 29 weeks' gestation. Pediatrics 2018; 141: e20172533.

12. Qiu X, Lodha A, Shah PS, et al; Canadian Neonatal Network Neonatal outcomes of small for gestational age preterm infants in Canada. Am J Perinatol 2012; 29: 87-94.

13. Allegaert K, Vanhole C, Casteels I, et al. Perinatal growth characteristics and associated risk of developing threshold retinopathy of prematurity. J AAPOS 2003; 7: 34-37.

14. Kavurt S, Ozcan B, Aydemir O, Bas AY, Demirel N. Risk of retinopathy of prematurity in small for gestational age premature infants. Indian Pediatr 2014; 51: 804-806.

15. Bardin C, Piuze G, Papageorgiou A. Outcome at 5 years of age of SGA and AGA infants born less than 28 weeks of gestation. Semin Perinatol 2004; 28: 288294.

16. Zhao M, Dai H, Deng $Y$, Zhao L. SGA as a risk factor for cerebral palsy in moderate to late preterm infants: a system review and meta-analysis. Sci Rep 2016; 6: 38853.

17. Stoknes M, Andersen GL, Dahlseng MO, et al. Cerebral palsy and neonatal death in term singletons born small for gestational age. Pediatrics 2012; 130: e1629-e1635.

18. Pinello L, Manea S, Visona Dalla Pozza L, Mazzarolo M, Facchin P. Visual, motor, and psychomotor development in small-for-gestational-age preterm infants. J AAPOS 2013; 17: 352-356.

19. Lindström L, Wikström AK, Bergman E, Lundgren M. Born small for gestational age and poor school performance - how small is too small? Horm Res Paediatr 2017; 88: 215-223.

20. Gur Z, Tsumi E, Wainstock T, Walter E, Sheiner E. Association between delivery of small-forgestational age neonate and long-term pediatric ophthalmic morbidity. Arch Gynecol Obstet 2018; 298: 1095-1099. 
21. Akova-Budak B, KivancSA, Olcaysu OO. Association of birth parameters with refractive status in a sample of caucasian children aged 4-17 years. J Ophthalmol 2015; 2015: 635682.

22. Lindqvist $S$, Vik T, Indredavik MS, Brubakk AM. Visual acuity, contrast sensitivity, peripheral vision and refraction in low birthweight teenagers. Acta Ophthalmol Scand 2007; 85: 157-164.

23. Rutstein RP, Wesson MD, Gotlieb S, Biasini FJ. Clinical comparison of the visual parameters in infants with intrauterine growth retardation vs. Infants with normal birth weight. Am J Optom Physiol Opt 1986; 63: 697-701.

24. Lindqvist S, Vik T, Indredavik MS, Skranes J, Brubakk AM. Eye movements and binocular function in low birthweight teenagers. Acta Ophthalmol 2008; 86: 265-274.

25. Evensen KA, Lindqvist S, Indredavik MS, Skranes J, Brubakk AM, Vik T. Do visual impairments affect risk of motor problems in preterm and term low birth weight adolescents? Eur J Paediatr Neurol 2009; 13: 47-56.

26. Ulusal görme taraması rehberi. Sağlık Bakanlığı (Ministry of Health) https://dosyamerkez.saglik.gov. tr/eklenti/31819, ulusal-gorme-taramasek636674105c05-4899-99f9-d5c20a336709pdf.Pdf?0 Published 2019. (Accessed 4 February 2020).

27. Grossman DC, Curry SJ, Owens DK, et al; US Preventive Services Task Force. Vision screening in children aged 6 months to 5 years: US preventive services task force recommendation statement. JAMA 2017; 318: 836-844.

28. Wallace DK, Morse CL, Melia M, et al; American Academy of Ophthalmology Pre-ferred Practice Pattern Pediatric Ophthalmology/Strabismus Panel Pediatric eye evaluations preferred practice pattern(r): I. Vision screening in the primary care and community setting; II. comprehensive ophthalmic examination. Ophthalmology 2018; 125: P184-P227.

29. Fenton TR, Kim JH. A systematic review and metaanalysis to revise the Fenton growth chart for preterm infants. BMC Pediatr 2013; 13: 59.

30. International Committee for the Classification of Retinopathy of Prematurity. The international classification of retinopathy of prematurity revisited. Arch Ophthalmol 2005; 123: 991-999.

31. Schalij-Delfos NE, de Graaf ME, Treffers WF, Engel J, Cats BP. Long term follow up of premature infants: detection of strabismus, amblyopia, and refractive errors. Br J Ophthalmol 2000; 84: 963-967.

32. Özdemir M, Koylu S. Ocular growth and morbidity in preterm children without retinopathy of prematurity. Jpn J Ophthalmol 2009; 53: 623-628.
33. Perez-Roche T, Altemir I, Gimenez G, et al. Effect of prematurity and low birth weight in visual abilities and school performance. Res Dev Disabil 2016; 59: 451-457.

34. Perez-Roche T, Altemir I, Gimenez G, et al. Face recognition impairment in small for gestational age and preterm children. Res Dev Disabil 2017; 62: 166173.

35. Ley D, Marsal K, Dahlgren J, Hellstrom A. Abnormal retinal optic nerve morphology in young adults after intrauterine growth restriction. Pediatr Res 2004; 56: 139-143.

36. Thordstein CM, Sultan BL, Wennergren MM, Törnqvist E, Lindecrantz KG, Kjellmer I. Visual evoked potentials in disproportionately growthretarded human neonates. Pediatr Neurol 2004; 30: 262-270.

37. Friedman DS, Repka MX, Katz J, et al. Prevalence of amblyopia and strabismus in white and African American children aged 6 through 71 months the Baltimore Pediatric Eye Disease Study. Ophthalmology 2009; 116: 2128-2134.e1-e2.

38. Multi-ethnic Pediatric Eye Disease Study G. Prevalence of amblyopia and strabismus in african American and Hispanic children ages 6 to 72 months the multi-ethnic pediatric eye disease study. Ophthalmology 2008; 115: 1229-1236.e1.

39. Pathai S, Cumberland PM, Rahi JS. Prevalence of and early-life influences on childhood strabismus: findings from the millennium cohort study. Arch Pediatr Adolesc Med 2010; 164: 250-257.

40. Robaei D, Kifley A, Gole GA, Mitchell P. The impact of modest prematurity on visual function at age 6 years: findings from a population-based study. Arch Ophthalmol 2006; 124: 871-877.

41. Fieß A, Kölb-Keerl R, Schuster AK, et al. Prevalence and associated factors of strabismus in former preterm and full-term infants between 4 and 10 years of age. BMC Ophthalmol 2017; 17: 228.

42. Bruce A, Santorelli G. Prevalence and risk factors of strabismus in a UK multi-ethnic birth cohort. Strabismus 2016; 24: 153-160.

43. Ip JM, Robaei D, Kifley A, Wang JJ, Rose KA, Mitchell $P$. Prevalence of hyperopia and associations with eye findings in 6- and 12-year-olds. Ophthalmology 2008; 115: 678-685. e1.

44. Fierson WM; American Academy of Pediatrics Section on Ophthalmology; American Academy of Ophthalmology; American Association for Pediatric Ophthalmology and Strabismus; American Association of Certified Orthoptists. Screening examination of premature infants for retinopathy of prematurity. Pediatrics 2018; 142: e20183061. Pediatrics 2019; 143: e20183810. 